\title{
"A sociedade aprendeu a cobrar do homem": entrevista com Ferréz
}

Por Christian Grünnagel ${ }^{1}$ e Doris Wieser ${ }^{2}$

\section{O que significa ser homem ou ser mulher para você?}

Eu mudei muito meu pensamento sobre isso. Eu era um cara bem preconceituoso. Porque nasci na periferia, a gente é muito machista lá. A literatura de certa forma me reeducou nisso. A literatura acabou me ajudando a entender o outro sexo e o mesmo sexo de forma diferente. Então ser homem é uma coisa difícil: segurar muitas responsabilidades, a carga fica com o homem. A cobrança da família, fala-se de direitos iguais da mulher, mas a cobrança fica muito do lado do homem. A sociedade aprendeu a cobrar do homem. O homem geralmente quando tem 50, 60 anos está acabado e a mulher ainda está nova. Não que a mulher não faça muita coisa, ela faz. Mas o homem acaba segurando a carga da família, as responsabilidades. Eu também fui educado para fazer isso.

Quer dizer que na periferia o modelo é muito tradicional.

O modelo é muito tradicional. Pode ser que não pareça, mas é tradicional.

Em sua opinião, que importância tem o machismo atualmente no Brasil?

Acho que tem um machismo muito grande. Esse machismo está nas igrejas evangélicas, na política, nas grandes empresas, nas pequenas empresas. O machismo hoje é fortíssimo.

\footnotetext{
${ }^{1}$ Doutor em letras românicas e professor do Instituto de Filologia Românica da Universidade de Giessen, Giessen, Alemanha. E-mail: christian.gruennagel@ romanistik.uni-giessen.de

2 Doutora em literatura ibero-americana e professora do Instituto de Filologia Românica da Universidade de Göttingen, Göttingen, Alemanha. Atualmente bolsista de pós-doutorado da Fundação Alexander von Humboldt na Universidade de Lisboa. E-mail: doris.wieser@phil.unigoettingen.de
} 
Em todas as partes.

Em todas as partes, mas as pessoas falam que não tem. Bahia e Pernambuco são os lugares onde tem mais machismo. Porto Alegre, Rio Grande do Sul, no Brasil todo também tem muito machismo.

\section{Quer dizer que depende um pouco da geografia.}

Também. Tem lugares em que as pessoas têm uma educação mais dura. A vivência mais dura, ela é por consequência mais machista.

Há uma socióloga australiana, chamada Connell, que propõe um modelo de vários projetos sobre a masculinidade. Ela fala de masculinidade no plural: "masculinidades". ${ }^{3}$ Você acha que há também vários tipos de masculinidade no Brasil atual?

Acho que tem várias formas. Cada um encara diferente. Tem gente que se acha machista e não é tanto, outros que não se dizem e agem como machistas, são patriarcais dentro da casa ou da empresa. Isso é variável mesmo.

No seu romance Capão Pecado temos, por exemplo, os playboys, o Matcherros e o Rael. Todos eles têm comportamentos diferentes. Você acha que há vários tipos de masculinidade no seu romance?

Acho que há várias camadas, como tudo na vida tem várias camadas. Tem uns que são mais superficiais, outros são mais profundos. Isso vai de pessoa para pessoa. Como eu digo, as pessoas não ficam paradas. Elas vão evoluindo. No livro você também tem essa preocupação de fazer o personagem evoluir. Tomando algumas decisões e mudando o caráter dele. Assim como na vida: tem pessoas que evoluem e tem pessoas que não.

Quer dizer que a masculinidade tradicional pode também evoluir.

Pode. É difícil, mas ela pode também.

\footnotetext{
${ }^{3}$ Para mais detalhes sobre o enfoque teórico de Connell, veja-se o texto introdutório deste dossiê.
} 


\section{E como você julga o estado atual da homossexualidade no Brasil?}

Eu acho que se criou uma ampla empatia, mas também se criou um problema. Por eles estarem lutando muito pelos direitos, estarem batendo de frente com a igreja evangélica, as pessoas ficaram meio recalcadas também. Então hoje é ou sim ou não, não tem o meio-termo. "Legal, o cara pode ser homossexual e pode ir para a igreja." Não, a igreja não quer. Acho que o problema está muito religioso. A intolerância está vindo muito da religião. Religião no Brasil é uma coisa muito triste, muito bagatela.

Sendo escritor, você vê alguma diferença no seu trabalho de criar um personagem do outro sexo, por exemplo, Paula como personagem feminina de Capão Pecado? Você trabalha diferente para criar uma personagem como Paula, em comparação com o Rael?

É diferente. É mais esforço para fazer uma mulher. É mais difícil entender a cabeça de uma mulher, é mais complicado. A mulher é um ser mais multifocal que um homem, mais bidimensional que um homem. O homem é mais centrado. Então fica mais difícil. Sempre tive dificuldade com personagens meninas. Só nesse último romance meu (Deus foi almoçar) é que eu consegui melhorar um pouco. Agora no novo que eu estou fazendo, só trabalho com uma personagem feminina. Acho que aí eu começo a melhorar de verdade. Começo trabalhar a cabeça uma menina de 14 anos. Então eu tenho esse desafio de entender a parte das mulheres. Mas hoje também estou mais cercado por mulheres. Eu era um cara sozinho, que não tinha namorada. Hoje eu sou casado com uma mulher, tenho uma filha mulher, minha mãe mulher, em casa. As irmãs dela são mulheres. Eu estou cercado de mulheres por todos os lados. A minha agente aqui fora é mulher, minha editora é mulher. Estou muito bem rodeado de mulheres. E estou tentando entender ainda, mas está melhorando.

Um axioma muito conhecido nos estudos de gênero é que sexo, o gênero do homem e da mulher, não é uma coisa natural. É uma construção cultural e social. Você acha que essa ideia é correta?

Eu também concordo. Tenho um amigo meu que é cross drag, que se veste de mulher. Eu acho que ele também está certo. Se o cara não tem vontade de se vestir de homem, por que ele tem que se vestir de homem? Por que é que ele tem que encarar ser homem? Por que é que 
ela tem que encarar ser mulher? Isso antigamente na minha cabeça não era viável, mas hoje já é. Entendo que isso é construído como o amor, a relação amorosa. O casal que quer ser feliz dentro de casa, ser religioso, são dogmas que a gente vai herdando, não é? São fenômenos culturais que foram criados em algum determinado momento. Alguém pegou o amor amoroso e pôs numa relação. Não tinha cobrança, era uma amizade e virou uma cobrança. Por que é que na amizade entre homens ou entre mulheres não tem cobrança? Geralmente você não tolera um amigo que fica te cobrando muito: "Que horas você chegou? Para onde é que você está indo? Está vindo de aonde?". Homem não é assim com outro, nem mulher com outra. Quer dizer que a relação entre os dois também é uma coisa criada, a noção de pertencimento, de casamento, de religião, de ir junto à igreja no domingo.

\section{Quer dizer que são coisas aprendidas?}

São coisas aprendidas. E a do gênero também, ser homem, ser mulher, ser filha, filho. É aprendido e só vem piorando. Você já treina a criança cozinhando, comprando Barbie, o menino já vai dirigir carrinho.

Você é um autor, uma das vozes mais destacadas da literatura marginal ou periférica. Você considera que esse movimento em primeiro lugar é literário ou social?

Caminha junto. É um movimento literário e social. Mais social do que literário, porque ele é mais importante na sociedade, mas é um fenômeno dos dois. De 1999 para cá, 48 autores aparecendo na cena, construindo saraus, construindo literatura, fazendo livros independentes, fazendo editoras, montando sites, blogs. Então é um fenômeno também literário e social. Todo mundo que trabalha com literatura marginal lida com a parte social também. Chegam às escolas, aonde outros autores não chegam. Chegam às cadeias, aonde os outros não chegam.

Você também criou uma marca de moda, a 1DASUL, que faz parte do movimento.

Faz parte. A gente produz livro, CD, roupa. A 1DASUL é uma forma de gestão da cultura. A gente é independente de projeto, independente de verba, independente de apoio. 
Você escreveu um manifesto em que diz que a literatura marginal é terrorismo literário. ${ }^{4}$ Mas no mesmo manifesto você escreve que tudo isso se passa sem querer agredir ninguém. Parece-me uma contradição: um "terrorismo" que não pretende "agredir ninguém". Em que consiste esse "terrorismo?

Eu falo assim no contexto porque é assim: querendo ser humilde, querendo dizer que a gente ainda é humilde, que a gente não quer passar por cima de ninguém. Mas ao mesmo tempo a gente vai entrar. Tipo assim: desculpa quem está atrás da porta, mas a gente vai entrar. A gente chegou. De certa forma o discurso vai falar isso. Me desculpem, mas eu vou passar. É terrorismo literário mesmo, chegar aonde ninguém chegou. Chegar de uma forma mais autêntica, mais real. Sem buscar nada. Fazer a literatura do jeito que ela é.

Na literatura brasileira houve muitos manifestos, sobretudo no modernismo, aqueles manifestos da vanguarda. O manifesto antropofágico, por exemplo. Em que medida o seu manifesto está na tradição desses manifestos?

Não tem ligação nenhuma. Eu não cheguei a ler o manifesto deles. Acho que sempre que esses movimentos se formaram, foram movimentos de elite. É uma outra parte da sociedade. Então o nosso não tem ligação nenhuma, a gente nem tem conhecimento nisso. A gente só fez o nosso, achava que era o momento de fazer um manifesto, uma coisa que falasse "chegamos". Então aí é de verdade o que aconteceu. Era importante marcar isso. Depois, o que vai ser feito com isso, se ficou para a história ou não, é outra coisa. Mas a gente marcou o resultado.

Talvez o manifesto de vocês esteja mais ligado com manifestos políticos, como o manifesto comunista?

Não, eu acho que o manifesto é do movimento punk. Eu vim assim de andar na rua com os moleques. De fazer de você mesmo a sua revolução, de meter a cara e ser agressivo. Eu vim da música, também. Não tenho muito o pé calcado em coisas que já foram concebidas. Meu

\footnotetext{
${ }^{4}$ FERRÉZ (2006). Manifesto de abertura: Literatura Marginal Terrorismo Literário. Disponível em: <http://editoraliteraturamarginal.blogspot.pt/2006/12/manifesto-de-abertura-do-livro.html> Acesso em: 12 jan. 2015.
} 
conhecimento veio da rua mesmo, da parte musical. E eu queria fazer um manifesto como um manifesto punk.

O movimento da literatura marginal pretende criar um espaço cultural para as pessoas da periferia. Mas também já tem algum impacto na cultura erudita. Em que medida a literatura marginal é importante para a literatura erudita e para a classe média e alta?

$\mathrm{Na}$ verdade eu não me importo com isso. Não me importo com academia, com prêmio, se eles vão ler. No fim o resultado está nas ruas. As pessoas da escola estadual leem, os moleques da periferia leem. Claro, chega também nessas classes, eles leem também, têm interesse. Mas eu não faço formatado para eles. Eu não penso de verdade se eles vão gostar ou não, o que eles vão achar, eu realmente não ligo.

E você está publicando agora por editoras como Planeta ou Objetiva, que têm uma distribuição muito maior do que aquelas editoras que nascem na periferia, onde o livro realmente é feito à mão. Seus livros agora já chegaram à Alemanha, por exemplo. Mesmo assim, você considera que a sua literatura continua sendo literatura marginal?

Lembram aquele caso do cara que roubou um trem, foi o maior assalto que já teve no mundo? O cara deixou de ser ladrão porque roubou muito dinheiro e ficou famoso? Não, não é? Ele continua sendo um criminoso. A literatura marginal é a mesma coisa. Não se deixa de falar do tema, só porque tem uma distribuição no Brasil todo. Pelo contrário: os moleques merecem serem distribuídos no Brasil. O trabalho é bom e merece chegar nos lugares. Então eu continuo tendo apoio de editoras pequenas. Tem uma editora em que eu trabalho esses livros, que não vão chegar nas grandes, são independentes. Mas ao mesmo tempo a gente também pode estar nos outros lugares. Afinal, a elite continuada que sempre fez livros neste país, ela nunca sofreu, nunca passou pelo que a gente passou e está se cuidando do Brasil todo.

Um dos temas mais importantes na sua literatura é a violência. Há vários tipos de violência: a do crime de narcotráfico, a violência doméstica, e às vezes eu me pergunto se há algo que se pode chamar "cultura de violência" em que todo o tipo de conflito se resolve com violência. O que você acha? 
Violência se tem em todo lugar no mundo. Até na cultura dos alemães tem uma violência muito forte, os americanos também, mataram todos os índios. Então todo país tem a sua parte violenta. Eu acho que um grande contraponto dos livros que eu faço é a violência e o amor, também. Porque, da mesma forma que tem a relação violenta, tem uma forma amorosa. Tem um cara que discutiu com o outro, mas às vezes andavam juntos, eram amigos, amavam um ao outro e depois isso se rompeu. Eu acho que o amor é uma coisa feia, uma coisa perigosa, que machuca, também. Por isso que vem a violência. Só há violência, porque se ama muito. Só se torna uma coisa feia, porque se tem um sentimento de muita cobrança, muito de amizade, muito de carinho, ele se sente traído. Então eu trabalho com os extremos. Meus personagens são violentos na hora de comer, de dirigir, são extremos, também.

Você diria que a violência também é uma forma de se comunicar?

Com certeza. Violência é uma cultura. Existe um estilo cultural atrás disso. É uma forma de comunicar-se, também, uma forma de fazer o corpo falar, de fazer a sua ação falar.

Há um sotaque cultural na violência de um país em comparação a outro?

Cada país tem a suas especificações, cada país tem a sua diferença. Num país muito organizado tem um certo tipo de violência. Você quer uma certa organização, não pode. Precisa de uma certa urgência, não pode. Tem outro país em que é tudo liberado e também tem um certo tipo de violência. Você quer ser mais certo, não pode. Então o julgamento quem dá é o homem. O homem que criou as regras para jogar. É uma coisa preconcebida. O que é violência, ou não. O que é acerto de contas, o que é vingança.

Eu acho muito interessante que você não só fala da violência do crime, mas também da violência dos namorados, de casais, de violência dentro da família. Parece-me que essa violência é gerada pelo ciúme, pela desconfiança constante. Eu me pergunto se na periferia a base da relação amorosa é esta: desconfiança e o ciúme. Existe também a fidelidade e a confiança como valor básico das relações? 
Existe, e existe a coisa do pertencimento. O maior problema é quando uma pessoa pensa que a outra pertence a ela. Isso gera desconfiança, cobrança, estrangulamento de relação. A pessoa sente que a outra lhe pertence. A frase que mais se ouve dentro de casa é assim: "Mas eu já estou com ele há seis anos". Mas você vai viver 70 anos, por que está pensando que está com ele há seis anos? Você não vai perder esse tempo, ele lhe pertence. A pessoa não se separa, porque já estão juntos por seis anos. É uma noção de pertencimento, você quer cobrar o tempo que ficou com a pessoa, ela te pertence.

Há outros autores que não são da parte do movimento da literatura marginal, mas que também escrevem sobre violência e sobre indivíduos desprivilegiados. Por exemplo, a Patrícia Melo ou o Luiz Ruffato. Qual, segundo você, seria a diferença entre a literatura marginal e a literatura deles?

A diferença é que quando uma pessoa passa pelo sofrimento, é diferente ela falar sobre o sofrimento. O sofrimento é uma "puta" escola, então a diferença só é essa. Quando o cara de favela lê, ele vai saber que aquilo ali não foi feito por uma pessoa de periferia. É só isso. Pode ser bem amarrado, bem estético, mas a pessoa vai falar "Esse daqui não passou por isso, o outro é legal, mas ele não passou por isso".

\section{Quer dizer que isso é um problema de realismo?}

Eu não vou poder fazer um filme de bangue-bangue e não ter troca de tiro. Eu posso falar "Tudo bem e tal", mas eu não sei o poder, o impulso da arma. Não sei como é quando um cara leva a bala, não sei como cai, não sei como ele fecha o olho. Eu não passei por isso. Posso falar que assisti, pesquisei, tudo bem, mas o sofrimento é a maior escola. Você ter passado por uma situação te dá a legitimidade para falar. Eles podem escrever sobre o tema normal, só que quem ler e for de comunidade sabe o que é de verdade ou não.

Um traço muito interessante para mim na sua literatura é que você geralmente não conta só uma história, nem duas, nem três, mas sim um grande número de histórias com um grande número de personagens. Foi uma decisão consciente? Por que é preciso, para você, dar voz a tantas pessoas? 
$\mathrm{Na}$ verdade tinha muito mais personagens e eu tive que cortar. E do meu livro novo eu tive que ficar pensando naqueles mesmos personagens, se não eu ia criar muitos mais. Tenho essa facilidade de criar personagens e tenho muita história para contar. Invento muitas histórias. A periferia é multifocal, é gente do Piauí, do Nordeste, do Sul, do Sudeste, de São Paulo, de Minas Gerais, de todo lugar, que convive ali. Então se tem uma riqueza muito grande. Falas, expressões, histórias. É isso que eu tento pôr nos meus livros. Eu queria ter menos personagens. É muito sofrido ter um monte de personagens e saber a cara de cada um, o caráter de cada um. Mas eu tenho esse excesso. Se veio, vamos usar.

Outros elementos muito chamativos na sua literatura são, para mim, as cenas de sexo. Tanto em Capão Pecado como em Manual prático do ódio há cenas muito fortes, que quase chamaria de pornográficas: sexo oral e anal de uma maneira bastante crua e um tanto violenta, também. Que conceito está atrás desse tipo de relação sexual? Talvez uma forma de homem de mostrar o domínio sobre a mulher?

Mostra isso porque é assim. Mostra a relação sexual assim, porque é desse jeito. O cara tem um domínio sobre a mulher. Muitas vezes é a mulher que tem um domínio sobre ele. A mulher é que vai à banheira, joga espuma, ela que provoca. No caso da Paula e do Rael, a Paula também toma atitude. Porque o Rael sozinho também não iria fazer nada. Tem uma correlação dos dois. No Manual prático do ódio tem as amantes, que é a vida criminal. Eu teria retratado a vida do bandido. Tem as amantes, as meninas que ficam com os caras. É só uma forma de tentar retratar. Em termos de relação eu não fico pensando o que seria o ideal. Eu não idealizo, só faço o que é e o que eu acho que tem que ser.

\section{É realismo então?}

É muito colocado na realidade. É ficção, mas tem muito o pé na realidade. Se fosse uma relação de sexo seria assim. Claro que eu imaginei a cena, mas é geralmente o que acontece. Então eu não tento falar "Mulher, você é linda! Tome suas flores", não é assim. É desse jeito, jogando champanhe, comemorando. 
Quer dizer que o conceito romântico do amor seria ridículo?

Nesse contexto, nessa época, sim. Tem uma parte romântica, na qual vem o carinho, mas é irreal. Lá onde a gente vive não é assim.

E até agora, pelo que eu sei, nos teus livros não há nenhuma mulher que faz algum tipo de rebeldia contra esse domínio físico masculino no sexo.

Tem a Aninha, por exemplo. Ela não pertence a isso. A Aninha, no Manual prático do ódio. Ela não participa de nada disso. Ela é uma mulher, está na dela, está tentando roubar, têm os sonhos dela, mas não está participando de nada disso. Ela não dá entrada. Ela está no meio dos homens, mas está na dela. No Capão Pecado, a própria Paula toma atitude. Ela toma a atitude de ferrar a vida do Rael. Ela é a ação, não é levada pela ação. O principal protagonista do livro é o Rael, que passa todo o livro, mas quem toma a ação é ela. Então também é um tipo de força fazer isso.

Muitas vezes eu tenho a impressão de que o comportamento das pessoas se traduz em expressões de ódio. Ódio que eles sentem por causa da marginalização, eles acham que têm o direito de pegar em coisas que não Ihes pertencem. Por exemplo, o Nego Duda, de Manual prático do ódio, diz "É hora de me vingar, a fome virou ódio e alguém tem que chorar". ${ }^{5}$ Esse tipo de literatura não contribui para consolidar o preconceito da classe média, que acha que um sujeito da periferia é um criminoso? A literatura marginal não deveria fazer o contrário: mostrar que nem todo o mundo que mora lá é criminoso?

Mas essa é uma forma preconceituosa de pensar. Porque é assim, primeiro os personagens foram roubados, a vida toda. Então o negro Duda foi roubado. A classe média e a alta tiraram deles a vida toda. Por isso que eles não têm nada. Eles foram desapropriados esse tempo todo, começa por aí. Segundo, aqui tem o professor, e ali o leitor. Eles não participam da vida criminal. Por que é que eles não chamam tanto a atenção? Por que é que o Paulo aqui e o Pablo lá não chamam tanto a atenção como os ladrões? Porque a gente tende a exacerbar sempre a violência. Então todo mundo presta mais atenção na vida criminal.

\footnotetext{
${ }^{5}$ FERRÉZ (2003). Manual prático do ódio. Rio de Janeiro: Objetiva, p. 41.
} 
As pessoas já têm esse ponto de vista.

É. Mas tem o Rael o tempo todo aqui e o Rael não é do crime. Ele toma uma atitude criminal uma hora, ele é levado, mas não é do crime. É uma pessoa boa. Então o protagonista, ele mostra para todo mundo que tem gente boa também. E tem várias pessoas que passam por aqui. Aquele senhor que é casado e tem que ir comprar Coca-Cola e ele não quer ir comprar, mas a mulher dele manda ele ir comprar. $\mathrm{O}$ menininho que vende a rosa no farol e aquela menina no carro humilha ele. Aquilo também pode ser visto como ódio de classe. Porque ele vai lá, dá a rosa para a mulher e, quando ele está precisando da mulher, a mulher nega para ele. Ela não quer ajudar ele e ela tem condição de ajudar. $\mathrm{Na}$ verdade é como eu falo, eu não ponho moral em nada. É o que é. Quem vai julgar é quem vai ler. Fala: "Nossa, tem cara que rouba lá, mas tem cara que lê". Se você é uma pessoa que tem a visão só para o ódio, então veja só o ódio. É a mesma coisa que olhar para um alemão e achar que todos são nazistas.

Mas muitas vezes os personagens que tentam sair daquele círculo vicioso da violência não conseguem. Por exemplo, o Rael, de Capão Pecado, se transforma em um assassino. Então para mim foi um final bastante pessimista.

Não, é realista. Pessimista é diferente. Pessimista é se eu não tivesse vivido isso.

O meu receio é que a classe média brasileira possa ver isso como uma confirmação dos seus preconceitos.

A classe média brasileira já vê a gente pior do que isso e muito mais. A classe média brasileira não dá oportunidade para ninguém. A primeira vez que eu chego a um festival desse e já ouço piadinha quando eu entro. "Olha a cota da periferia já chegou!" Então eles são assim.

\section{E vocês estão no mesmo hotel.}

A gente está no mesmo hotel, mas não somos iguais, por exemplo. Eu não tenho nada a ver com eles. Não tenho um personal trainer, não tenho um médico particular, eu estou vivendo na mesma situação em que eu vivia antes. Moro em uma periferia do mesmo jeito. Então é diferente. Eles já 
têm essa visão. Eu não me preocupo com a visão que eles vão ter através dos livros. Eu só quero fazer uma coisa que não fuja do que eu vivi. Eu tinha 22 amigos quando eu era pequeno, perdi 19 assassinados. Eu passei por isso. A minha visão simplesmente é o que é. Não estou defendendo o livro, porque o livro está aí e cada um interpreta de uma forma. Mas eu entendo o que você está falando, que a pessoa pode ler e falar: "Nossa, é assim?", mas é assim. Foi assim naquela época, hoje é diferente. Naquela época teve coisa que foi pior, que eu não posso pôr em livro. E eu passei isso. Era legal só a pessoa ter a oportunidade de saber que aconteceu isso. Que amigos se juntaram para roubar o banco, que também morreram pessoas que eram inocentes, eram legais. Queria que o leitor sentisse o que senti quando eu perdi meus amigos. Que ele sentisse ao final isso, não levasse alegria para casa. Falar assim: "Porra, era um cara legal! Pessoas legais morrem, também. Pessoas legais também entram no crime. Pessoas legais também fazem merda." O que se refere a um marginal. $\mathrm{O}$ marginal é o ato criminal. Só. O resto é tudo igual à gente.

E agora, que o Brasil se está preparando para a Copa do Mundo, você acha que aquelas medidas tomadas para pacificar as favelas vão trazer algum resultado em longo prazo?

Não. Você não manda ajudar uma comunidade com uma pessoa que mata a comunidade. Ou o cara vai lá matar a população, ou ele vai lá ajudar a população. As duas coisas juntas, não dá. Não se faz movimento social com a polícia. É o que eu acho.

E todas aquelas manifestações deste ano [2013], nas cidades grandes. Você acha isso um bom sinal?

Eu acho um bom sinal, acho que as pessoas estão acordando também. Mas eu acho que ainda tem que engrossar mais. A periferia ainda não participou das manifestações da forma que ia participar. A periferia está preocupada em comer, sobreviver. Então não pode parar o dia de trabalho. Mas eu acho um bom sinal. É um começo de alguma coisa.

\section{É sobretudo a classe média que faz essas manifestações.}

A classe média está mais ativa, mas tem muita gente também de periferia. Falta engrossar mais. Só onde eu moro são 380 mil pessoas. Se 
todos fossem para a rua, aí acabou mesmo. Ainda falta, acho que um dia ainda vai. 